\title{
APUNTES SOBRE DON QUIJOTE COMO NARRADOR
}

La crítica cervantina que ha estudiado últimamente las narraciones intercaladas en la Primera Parte del Quijote omite de su análisis los cuentos que narra el propio don Quijote. Los omite sin explicación (Immerwahr, Williamson) o los clasifica de manera excluyente:

Upon close examination all the narrators can be divided into two opposing groups, and the novel is found to be structured on a polarity between these two sets of narrators. The first is the over-all narrator complex of Cide Hamete Benengeli and the unnamed editor, the segundo yo, who compiles the text. This much is obvious. To this group must also be added the tales Don Quijote relates because his stories belong to the chivalric vision exemplified by the control genre, the libro de caballerias. The projection of this vision is the underlying thrust of the novel as a whole (Dudley, 357-58) '.

Para enfocar a don Quijote como narrador, procede definir y delimitar la cuentística propiamente quijotesca. Partimos, para ello, de la única lista que conocemos de la misma:

Don Quijote's own tales in Part One (Alifanfarón in Chapter xvii, El Caballero del Sol in Chapter xxi, and el Caballero del Lago in Chapter 1) are all novels of chivalry in miniature. The first is a parody and presents situations concerning young lovers, foreshadowing the matter of the interpolated tales. The second, suitably associated with the finding of the helmet of Mambrino, defines the role Don Quijote seeks for himself, while the third tells of a knight's search for his own identity. In the last case the story forms part of his discussion with the Canon of

${ }^{1}$ En estudios no dedicados concretamente a la cuentística interpolada en la Primera Parte, es frecuente tratar lo narrado por don Quijote en el mismo plano que lo narrado por otros. Véase, por ejemplo, El Saffar, 67. 
Toledo, and anticipates Don Quijote's own dilemma in Part Two (Dudley, 358).

Ahora bien, existe, a primera vista, una importante diferencia cualitativa entre los tres casos citados por el profesor Dudley, entre la primera narración de su lista y las otras dos: en el capítulo 17, relacionado con Alifanfarón, Don Quijote se halla en trance descriptivo-transformativo, en el proceso mismo de 'hacer' ejércitos guerreros de las manadas de ovejas que tiene delante, mientras que en los otros dos casos citados el protagonista no está 'viendo' algo, sino narrando, simple y llanamente (y muy a sabiendas de lo que hace), un relato, algo ni vivido ni visto por él en ese momento. La minitrama de Alifanfarón, su hija y el pretendiente cristiano de ésta, participa, aunque sustancialmente fictiva, de esa fase transformativa del protagonista que en otras ocasiones nos ha brindado, aunque con menos detalle, una 'princesa' hurtada por encantadores $(I, 8)$ y una 'fermosa doncella' en dificultoso apremio $(I, 16)$. Nos parece que lo que procede de la activa transformación quijotesca de la realidad (trozos de trama vinculados a la propia transformación -ya dados directamentecomo en los capítulos 8 y 17, ya indicados por Cide Hamete, como en el capítulo 16) no debiera clasificarse junto a lo que procede de los momentos en que el protagonista, con toda tranquilidad, sin la agitación propia del trance transformativo, narra, que no describe, un cuento.

Con este criterio de diferenciación -entre descripción vivida y relación propiamente narrada, con finalidad y conciencia de narrador - quedaría descartada la primera de las 'narraciones' citadas por el profesor Dudley, y restarian así, según la lista base de éste, sólo dos momentos de la Primera Parte en que don Quijote asume sin ambages, en su acepción corriente, el papel de narrador. Es el caso, sin embargo, que los estudiosos de la narrativa intercalada en el Quijote de 1605, y el profesor Dudley muy concretamente en su citada lista, omiten una instancia que nos parece cumplir del todo con lo que ha de ser una narración quijotesca:

- Ya te tengo dicho antes de agora muchas veces, Sancho - dijo don Quijote-, que eres muy grande hablador que, aunque de ingenio boto, muchas veces despuntas de agudo; mas, para que veas cuan necio eres tú y cuan discreto soy, quiero que me oyas un breve cuento. Has de saber que una viuda hermosa, moza libre y rica, y sobre todo, desenfadada, se enamoró de un mozo motilón, rollizo y de buen tono; alcanzólo a saber su mayor, y un día dijo a la buena viuda, por vía de fraternal reprehensión: «Maravillado estoy, señora, y no sin mucha causa, de que una mujer tan principal, tan hermosa y tan rica como 
vuestra merced, se haya enamorado de un hombre $\tan$ soez, $\tan$ bajo y tan idiota como fulano, habiendo en esta casa tantos maestros, tantos presentados y tantos teólogos, en quien vuestra merced pudiera escoger como entre peras, y decir: Este quiero, aqueste no quierow. Mas ella le respondió, con mucho donaire y desenvoltura: «Vuestra merced, señor mío, está muy engañado, y piensa muy a lo antiguo si piensa que yo he escogido mal en fulano, por idiota que le parece; pues para lo que yo le quiero, tanta filosofia sabe, y más, que Aristóteles» $(I, x x v)^{2}$.

Se comprende que pueda omitirse lo citado al hacer el recuento de los momentos 'narrativos' del protagonista cervantino, pues el cuentecillo tradicional está en el polo opuesto de la temática caballeresca que se suele identificar con don Quijote (Barrick, 127-28). Si se contrasta esta 'corregida' lista de narraciones quijotescas con la propuesta por el profesor Dudley, resulta claro que carece de pie su clasificación de don Quijote, en cuanto narrador, con Cide Hamete y su cervantino editor. Como se ha visto el principal argumento aducido por el estudioso cervantista, la invariabilidad caballeresca de la temática de don Quijote, no refleja la realidad textual, ya que una de sus tres narraciones representaría el polo opuesto de esa categoría.

Resumamos lo que las salvedades, distinciones y adiciones llevadas a cabo indican. Resulta claro, pensamos, que son tres las intervenciones propiamente narrativas del protagonista en la Primera Parte, descontando, por un lado, lo que don Quijote dice (que no narra) como parte de una experiencia transformativa y añadiendo, por otro, la ocasión en que patentemente narra un cuentecillo de carácter popular: un mini-cuento caballeresco (cap. 21), seguido muy de cerca por ese relato popular (cap. 25); y seguido éste, aunque ya a los muchos capítulos, por otro minicuento caballeresco (cap. 50). En esas tres ocasiones, don Quijote, consciente narrador, relata, desde dentro del texto, como Sancho o Dorotea (y en modo alguno como Cide Hamete Benengeli o el editor cervantino), una materia cuentística nítidamente distinguible y de características narrativas parecidas a otras interpolaciones cuentísticas de esa Primera Parte.

Así, pues, si la cuentística quijotesca indicada se caracteriza por la brevedad, no menos breve es lo narrado por Sancho (la inacabada historia de la pastora Torralba y el cabrero Lope Ruiz),

${ }^{2}$ Chevalier (167) clasifica el relato de 'cuentecillo tradicional', indicando su aparición en Castillejo y su repetición en otras obras de Cervantes. El erudito identifica sólo otra interpolación de semejante material en la Primera Parte del Quijote, y esa otra sólo aludida. Es de notar, frente a la lista compilada por Chevalier (166-69), que la Segunda Parte, que ofrece poca cuentística interpolada, recoge, sin embargo, hasta siete cuentecillos tradicionales. 
que Dudley incluye en su estudio. La brevedad indicada es función, en gran medida, de lo que narra el protagonista: en el caso de las dos narraciones caballerescas, su índole esquemática (versiones de incidentes caballerescos) se debe a una finalidad concretamente ejemplar cara a Sancho o el canónigo; y en el caso del cuentecillo tradicional, la forma misma exige la brevedad. Y si las narraciones de don Quijote carecen del biografismo que caracteriza a muchos de los demás cuentos intercalados en la Primera Parte, cabe notar que dos de esos cuentos (el de Sancho, ya indicado, y 'El curioso impertinente') carecen también de elementos biográficos.

No vemos, pues, razón alguna para excluir el fruto de don Quijote-narrador del número de las narraciones insertas en la Primera Parte. Se comprende que el incluirlas complique algo la reducción formularia de ese material, pero el no hacerlo, sin más, como Immerwahr, o con razones desprendidas de una compilación incompleta del material, como Dudley, resulta poco provechoso.

Ahora bien, ¿qué cabe deducir de la legítima inclusión de lo narrado por el protagonista en el contenido cuentístico de la Primera Parte? Sobre todo, que su inclusión complica barrocamente ese conjunto cuentístico. En términos temáticos, gracias a una aportación quijotesca se incorpora el elemento más explícitamente picante (iy nada menos que en boca del idealizante protagonista!) del texto; y gracias a sus otras aportaciones se han de incluir, junto a tramas pastoriles, amorosas y de otra índole, dos que son plenamente caballerescas ${ }^{3}$.

Esto último -que Dudley se inhibe de constatar con separar las mini-novelas caballerescas del protagonista, como se ha visto, del resto de la cuentística inserta en la Primera Parte- es barrocamente significativo, puesto que los mini-cuentos caballerescos de don Quijote añaden, desde dentro de la parodia de lo caballeresco, ecos, no poco discordantes, por auténticos, del modelo parodiado. $\mathrm{Y}$ barrocos y especialmente cervantinos resultan, asimismo, la polarizada variedad temática de las narraciones del protagonista y el orden de su inserción en el texto. En lo que respecta a la sustancia temática, se destaca, con incluir el verdoso cuentecillo tradicional, una heterogeneidad polarizada de marcado sabor barroco. Y en lo que se refiere a la distribución textual

${ }^{3}$ No serian las únicas si se tiene en cuenta la trama caballeresca ideada en parte por el cura y en parte por Dorotea, pero ésta, a diferencia de las narradas por don Quijote, se 'representa' burlescamente. Para el significado literario del segundo de los cuentos caballerescos de don Quijote (I,50), véase el estudio del profesor Rull. 
de ese discordante material cuentístico, cabe notar una disposición textual que parece ideada para rendir el máximo impacto de incongruente heterogeneidad: en la chocante proximidad entre la primera inserción caballeresca y el popular y picante cuentecillo; y en la colocación de éste, cargado de pimienta, justo entre dos elementos caballeresco-idealizantes.

Es más, si uno vuelve analíticamente sobre el cuentecillo popular de don Quijote, concediendo lo injusto e ilógico de su omisión de entre el material cuentístico atribuido a su persona, se observará que Cervantes añade, con incorporarlo al texto, mucho más malabarismo literario, y de carácter no poco barroco, del que salta inmediatamnte a la vista. Recordemos el contexto en que ello ocurre. Don Quijote, deseoso de que Dulcinea sepa de la penitencia que por su amor piensa hacer en Sierra Morena, decide enviarle a Sancho con una carta y los apropiados informes. Se ve forzado, pues, a descubrirle al escudero que Dulcinea es, de hecho, Aldonza Lorenzo. Ante el chocante descubrimiento, Sancho nos ofrece una descripción bastante completa de Aldonza Lorenzo, destacando, a través de su aspecto físico y su situación social, nada ideal el primero ni aristocrática la segunda, su patente divergencia de la idealizada Dulcinea. En este punto, y muy a la defensiva, don Quijote narra el cuentecillo tradicional cuya lección ( ... para lo que yo le quiero, tanta filosofía sabe, y más, que Aristóteles") ha de aplicarse a la fundamental discrepancia Aldonza/Dulcinea señalada por Sancho: a saber, para base real de mi idealización, objeto idealizado de mi amor 'platónico' 4, me sirven perfectamente la figura y la persona de Aldonza.

Sancho -y el lector, por cierto- acepta la aplicación de esa lección al contexto descrito, y la novela continúa sin más. Pero si el lector dejara funcionar su juicio crítico - siempre algo abandonado ante lo literario, sirviendo eso mismo de base para el juego, cervantino y barroco, entre literatura y vida: la una, metafóricamente, tan 'engañosa' como la otra- no dejaría de observar el enorme salto de credulidad, de radical suspensión de juicio crítico, que esa aceptación supone. Cervantes logra que aceptemos como convincente y 'racional' una aplicación ejemplar de lo literario (el picante cuentecillo) al contexto vivido de la novela (las discrepancias Aldonza/Dulcinea señaladas por Sancho) utilizando adrede, en lo literario, elementos contrapuestos al contexto novelístico al que se ha de aplicar su lección: en la vida de la novela se trata de lo femenino como objeto suficiente (Al-

${ }^{4}$ Es justo en este contexto, en este diálogo con Sancho, que Cervantes hace que don Quijote utilice ese adjetivo que hasta nuestros dias acarrea la noción de amor idealizado. 
donza), mientras que en el cuentecillo tradicional es masculino el elemento (mozo motilón) cuya deficiencia se define; y, sobre todo, en la vida de la novela la suficiencia que destaca la lección va dirigida a la idealización (Dulcinea) de lo anti-ideal y material (Aldonza), mientras que en el ejemplo literario se trata de lo opuesto, del rechazo de factores intelectuales, espirituales, a favor de la suficiencia física y material, concretamente sexual s. El lector que analice su acrítica aceptación de la lección del cuentecillo picante no puede menos que reconocer, a posteriori, la capacidad de 'engaño' que posee la literatura, metáfora de la vida.

Siempre se podrá argüir que no hay en ello intención barrocamente desafiante, que don Quijote, Cervantes, buscando un apropiado ejemplo popular da incidentalmente con el que da, como pudo haber dado con cualquier otro cuentecillo tradicional, nada contradictorio de la situación a la que se aplica en los elementos que conducen a su ejemplar lección. No creemos, desde luego, que el desafío paradójico sea jamás inserción accidental, impensada, en Cervantes, en el escritor barroco para quien la literatura, en la revelación de su consensual 'engaño', era legítima metáfora de la vida. Mas ello quizás se pueda comprobar en términos más objetivos al considerar la finalidad concreta del cuentecillo tradicional, portador de una lección aplicable a una situación concreta ${ }^{\circ}$. Si se revisan los otros cuentecillos tradicionales que Cervantes insertó en el Quijote con fin ejemplar, se destaca lo que es lógico, dada la finalidad ejemplar: una concordancia entre los elementos de lo que se narra y la realidad novelística a la que se ha de aplicar como lección. Eso es lo normal y esperado, por una lógica de mínima eficiencia. Excepto, naturalmente, cuando el escritor barroco subvierte muy adrede esa concordancia para revelar, con malabarismos de paradoja, el 'engaño' que, como la vida misma, opera consensualmente la literatura, su barroca metáfora.

En conclusión, la omisión erudita del chascarrillo de la viuda rica y el mozo motilón del cuadro cuentístico que el mismo protagonista, como narrador, incorpora a la Primera Parte, supone no sólo un empobrecimiento de ese cuadro narrativo, sino que impide la percepción del esfuerzo cervantino por destacar en el mismo una muy barroca variedad cualitativa. Sobre todo, se des-

${ }^{3}$ El estado religioso del 'mozo molitón' subraya aún más, con su carácter sacrilego, la finalidad erótico-sensual, material, que transmite el cuentecillo.

' Chevalier no estudia la función literaria del cuentecillo tradicional inserto en el Quijote, pero basta repasar su compilación de éstos para observar que Cervantes los inserta casi invariablemente con fin ejemplar, como ejemplo aclarador de una situación en la realidad novelística. 
aprovecha con ello el análisis detallado de uno de los momentos del Quijote que mejor se presta a la percepción concreta (porque ello es, naturalmente, base de toda la obra) del uso barroco de la literatura como metáfora de la vida en su extraordinaria capacidad de 'engaño' consensual.

Pensamos que la chocante 'salida de tono' que el cuentecillo tradicional supone en boca de don Quijote lleva una doble finalidad literaria: destacar exageradamente, por su polarizada diferencia cualitativa, la buscada variedad estética; y, mediante el 'shock' que supone lo absolutamente inesperado que resulta en boca del protagonista, servir de llamada de atención al dormido juicio crítico del lector, de revelador 'desengaño' en éste al darse cuenta de que el escritor le ha metido, con su ejemplo literario, gato por liebre.

\section{ALFRED RODRÍGUEZ \\ DEANNA CORNEJO-PATTERSON}

\section{OBRAS CONSULTADAS}

BARRICK, M. E., "The Form and Function of Folktales in Don Quijoten, The Journal of Medieval and Renaissances Studies, 6, 1976, 101-38.

Chevalier, M., «Literatura oral y ficción cervantina», Prohemio, 5, 1974, 161-96.

DudLEY, E., «Don Quijote as Magus: The Rhetoric of Interpolation», Bulletin of Hispanic Studies, 49, 1972, 355-68.

El Saffar, R., Distance and Control in Don Quijote. Chapel Hill, North Carolina Studies in Romance Languages and Literatures, 1975.

IMMERWAHR, R., «Structural Symmetry in the Episodic Narratives of Don Quijote, Part Onew, Comparative Literature, 10, 1958, 121-35.

Rull, E., «El arquetipo del caballero en el Quijote, a través de los 'topoi' de la laguna y el palacio encantados", Anales Cervantinos, 19, 1981, 57-67.

Wuuamson, E, «Romance and Realism in the Interpolated Stories of the Quijoten, Cervantes, 2, 1982, 43-67. 